\title{
Architecture and Social Continuity at Neolithic Tell Sabi Abyad III, Syria
}

\author{
Peter M. M. G. Akkermans and Merel L. Brüning \\ Leiden University, The Netherlands
}

The Neolithic site of Tell Sabi Abyad lies about 30km south of the border between Syria and Turkey in the upper valley of the Balikh river, a perennial tributary of the Euphrates. The site consists of a group of four prehistoric mounds -Tells Sabi Abyad I to IV-situated at a distance of only a few dozen to a few hundred metres from each other. In the past 25 years, excavations have been carried out predominantly at the largest of the four mounds, Tell Sabi Abyad I, which has a five-hectare area of settlement dating from the seventh to sixth millennium BC (see Akkermans et al. 2014 for a recent account).

However, in 2005 and in 2010, extensive soundings also were undertaken at the small and low, onehectare mound of Tell Sabi Abyad III (Figures 1-2), which revealed a series of settlements dated to the very beginning of the seventh millennium, ca. 70006700 BC (see Nieuwenhuyse et al. 2010 for a review of the radiocarbon dates from Tell Sabi Abyad III and the neighbouring mounds of Tells Sabi Abyad I and II). Significantly, the local occupations coincide with the introduction of pottery at the site (and in the NorthSyrian region in general). The earliest pottery-bearing layers at Tell Sabi Abyad III were immediately above deposits entirely devoid of ceramics. No stratigraphic or other hiatus occurred between the lower, aceramic levels and the upper, ceramic levels. Other than the ceramic evidence, there is proof for considerable continuity, rather than change, at the transition from the Pre-Pottery Neolithic to the Pottery Neolithic (Akkermans et al. 2006; Nieuwenhuyse et al. 2010).

Contemporary levels were also exposed in deep trenches in the north-western part of Tell Sabi Abyad I, as well as in the upper strata at neighbouring Tell Sabi Abyad II (see Nieuwenhuyse et al.2010). While the relevant layers at the latter two sites were uncovered over restricted areas, at Tell Sabi Abyad III they were unearthed at a very substantial scale, over 700 square metres. It is still difficult to establish the extent of the settlement at Tell Sabi Abyad III, although there is reason to believe that it was quite limited, with free-standing buildings comprising only a small portion of the mound, leaving large areas open and used only for waste disposal and the occasional construction of fireplaces. The sequence of occupations of the early seventh millennium at the site may perhaps have covered around a quarter of a hectare. It is, however, important to realize that similar tiny habitations were found very nearby (at Tells Sabi Abyad I and II), suggesting that the local community was divided into small and dispersed groups (see Akkermans 2013).

This paper is dedicated to our friend and colleague Olivier Rouault, whose enormous contribution to the archaeology of the Near East deserves nothing but gratitude, and is concerned with the astoundingly

Figure 1. The small mound of Tell Sabi Abyad III during the excavations in 2010 (photo $\odot$ Peter Akkermans - Tell Sabi Abyad Archive).

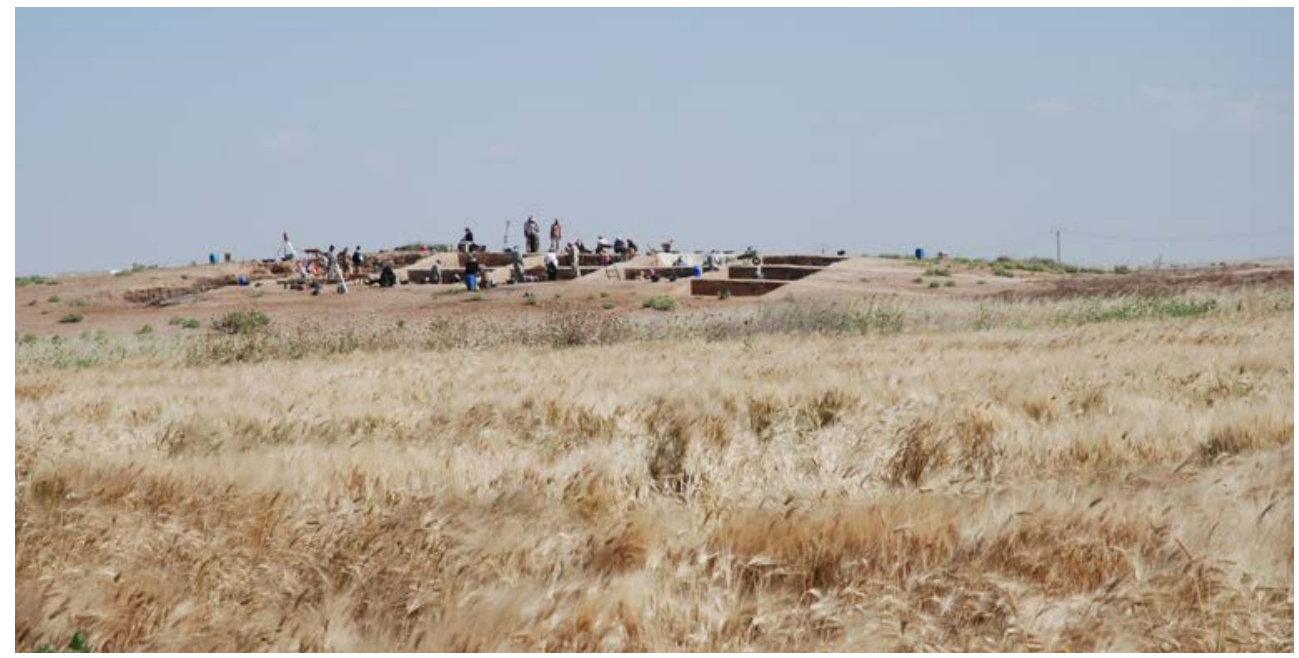




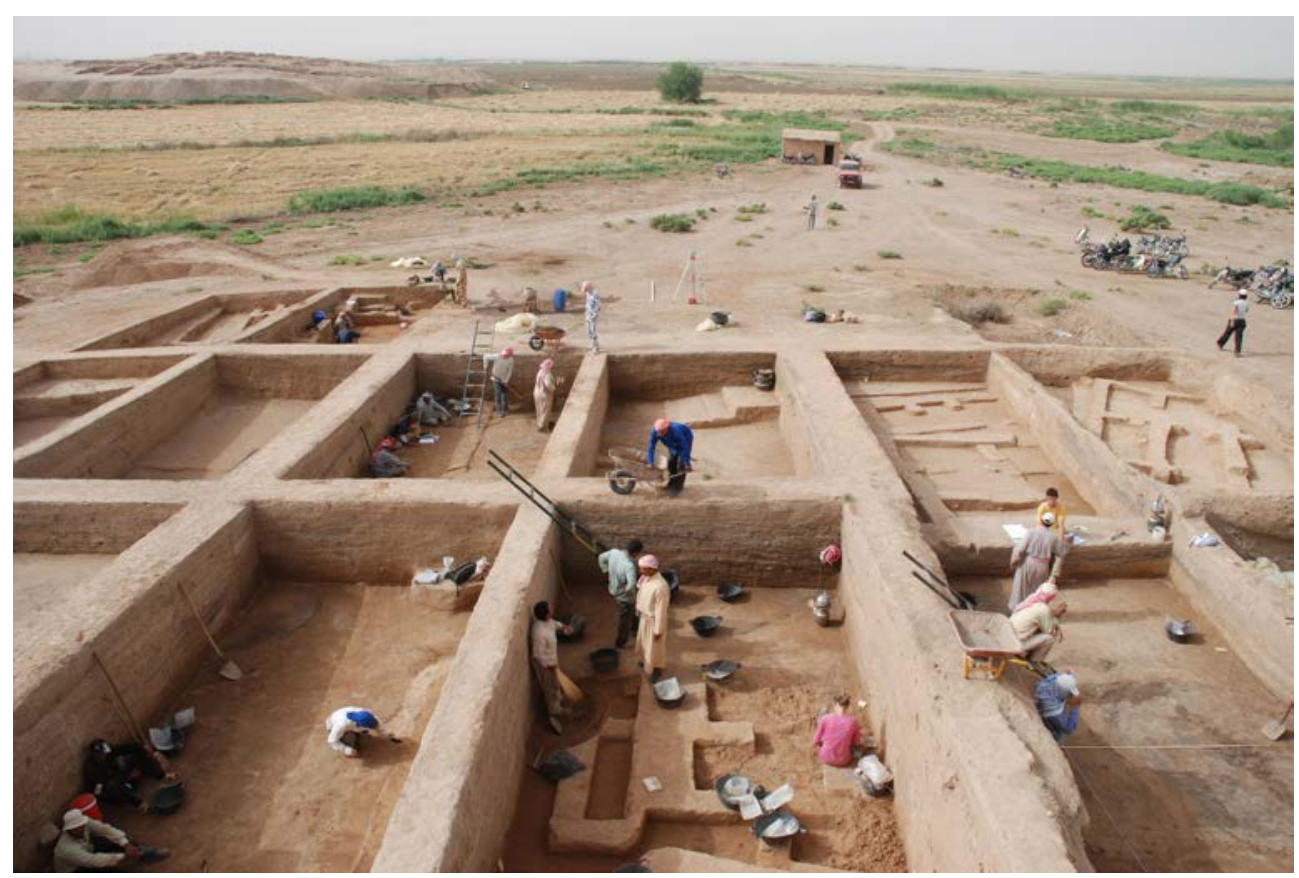

Figure 2. The trenches at Tell Sabi Abyad III in 2010, with, in the background, the site of Tell Sabi Abyad I (photo 1 Peter Akkermans - Tell Sabi Abyad Archive).

uniform Neolithic architecture at Tell Sabi Abyad III. From the beginning of the seventh millennium, the free-standing and highly symmetrical, tripartite buildings were all set on platforms and remained very similar in layout and size for several centuries, until a change towards more irregular and 'organic' structures occurred around $6700 \mathrm{BC}$. A word of caution: this article has to remain a brief interim evaluation, since most of the materials found in the excavations at Tell Sabi Abyad III are still under study and the conclusions presented here may be revised once the data have been fully analyzed.

\section{Architectural Characteristics}

Tell Sabi Abyad III had a consistent and well-ordered pattern of construction throughout its sequence of settlement. The buildings were all free-standing and surrounded by large open yards characterized by an accumulation of innumerable thin layers of soil, ashes, building debris, etc. The structures at the site were distinctly tripartite in layout, with each rectangular building comprising a relatively wide central hall flanked by parallel rows of narrow but long-drawn rooms along each of the long sides, usually with a smaller cubicle at the rear end (see Figures 3-6). Sometimes the large hall in the middle was also divided into smaller compartments. The tripartite structures were perfectly symmetrical in plan, and they were all roughly the same size, between 30 and 40 square metres.

The outer entry (about 60 to $70 \mathrm{~cm}$ wide) to these buildings was always on one of the short sides, which gave access to the central hall. The other rooms were each separately accessible only from the central hall (cf. Figure 3). Both the floors and walls in the buildings were coated with a reddish mud plaster $1-2 \mathrm{~cm}$ thick in places. Occasional traces of white (gypsum) plaster were found on the interior facades. The room sizes in each of the tripartite buildings were small, ranging between 0.6 and 2.4 square metres only. Without exception the rooms were (very) narrow, with their width hardly exceeding $50 \mathrm{~cm}$ in some cases (see for example Figure 6). Hence it is difficult to see how these limited spaces served in everyday domestic life; did people, or perhaps even entire families, sit, eat, sleep, and so on, in these 'coffin'-like spaces? One option is that the exposed walls did not delimit rooms but were merely intended to support a slightly raised floor, with air circulating below. However, the specific layout, the careful plastering of walls and floors, and the presence of obvious doorways argue against such an interpretation. Another option is that the architectural features represented a ground floor primarily for storage, while the inhabitants themselves lived and worked in an upper storey of the building (or perhaps in the smaller rectangular structures that accompanied the tripartite buildings; see below). Although this possibility cannot be excluded, there is no unambiguous evidence for it at this point.

All buildings were made of large clay slabs or, perhaps, bricks up to $1-1.2 \mathrm{~m}$ long, $35-40 \mathrm{~cm}$ wide and $10-12 \mathrm{~cm}$ thick. The slabs were set in thick layers of clay mortar, which was used only in the case of the horizontal joints, not the vertical ones. These slabs were the predominant building material at the various mounds of Tell Sabi Abyad in the period between 7000 and 6200 BC (cf. Akkermans et al. 2006; Akkermans et al. 2014: 32). 
Figure 3. Plan of a typically tripartite and highly

symmetrical building at Tell Sabi Abyad III, ca. 6900 BC. The building stood upon a platform made of large clay slabs (drawing by Martin Hense Tell Sabi Abyad Archive).

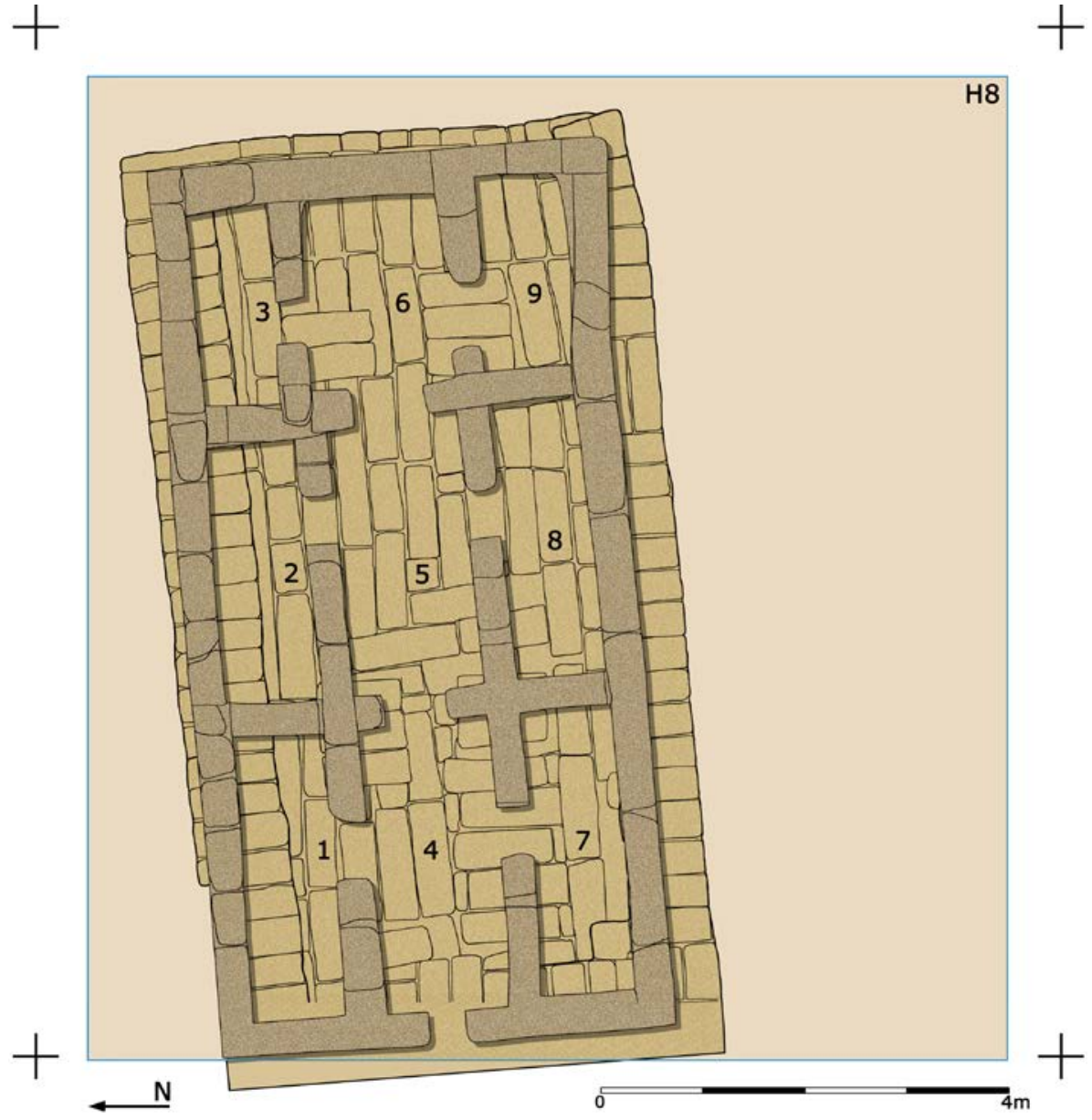

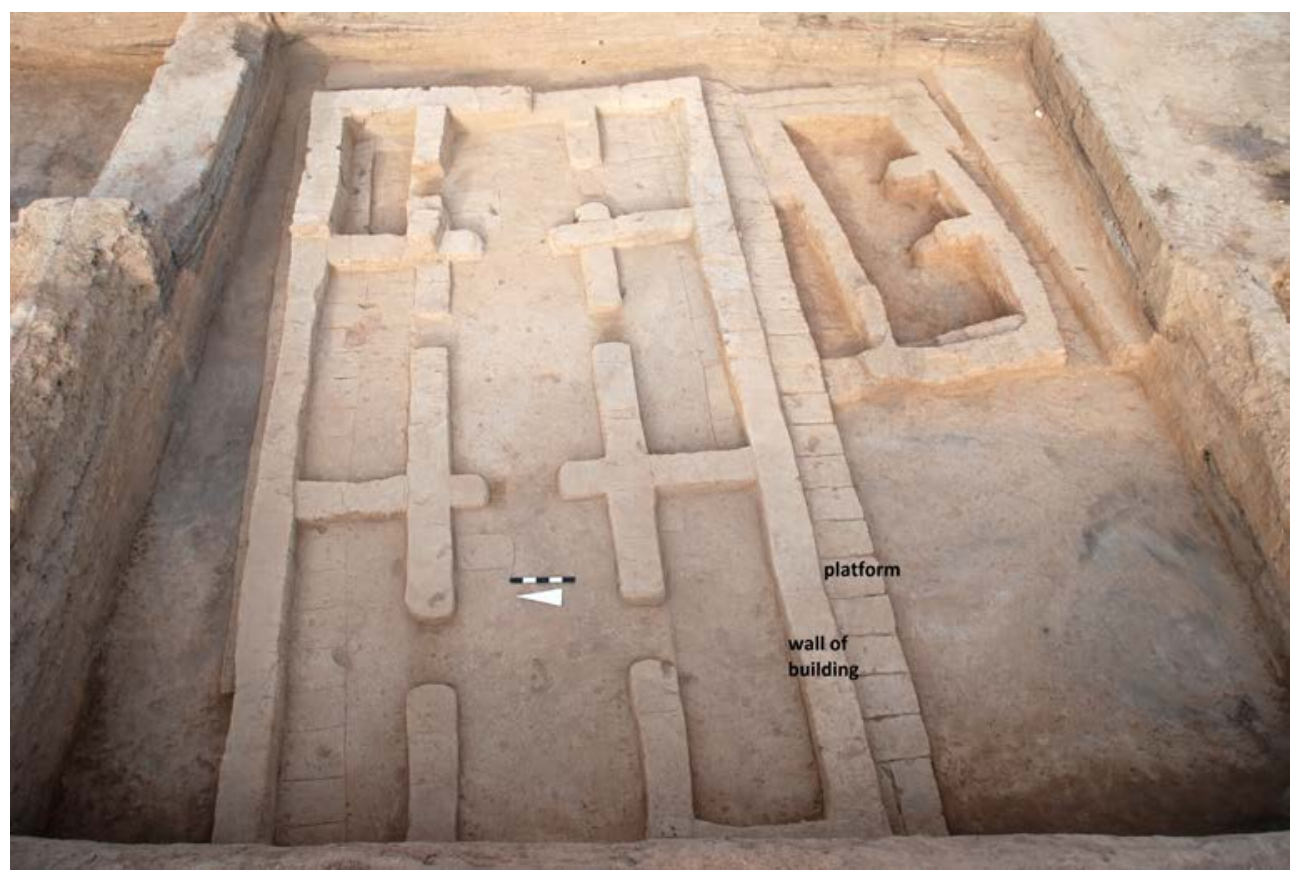

Figure 4. The tripartite building in square H8 at Tell Sabi Abyad III, ca. 6900 BC. The platform below the building is clearly visible along the edges of the structure (photo @ Peter Akkermans - Tell Sabi Abyad Archive).

Significantly, the buildings all stood upon low, rectangular platforms up to 10 by $7 \mathrm{~m}$ in extent and up to $1 \mathrm{~m}$ in height (Figures 3-6). The platforms were widely used between about 7000 and $6200 \mathrm{BC}$, although their abundance gradually declined after $6700 \mathrm{BC}$, when their construction moreover tended to be more haphazard and less careful than before (see Akkermans et al. 2011 for a detailed account). 


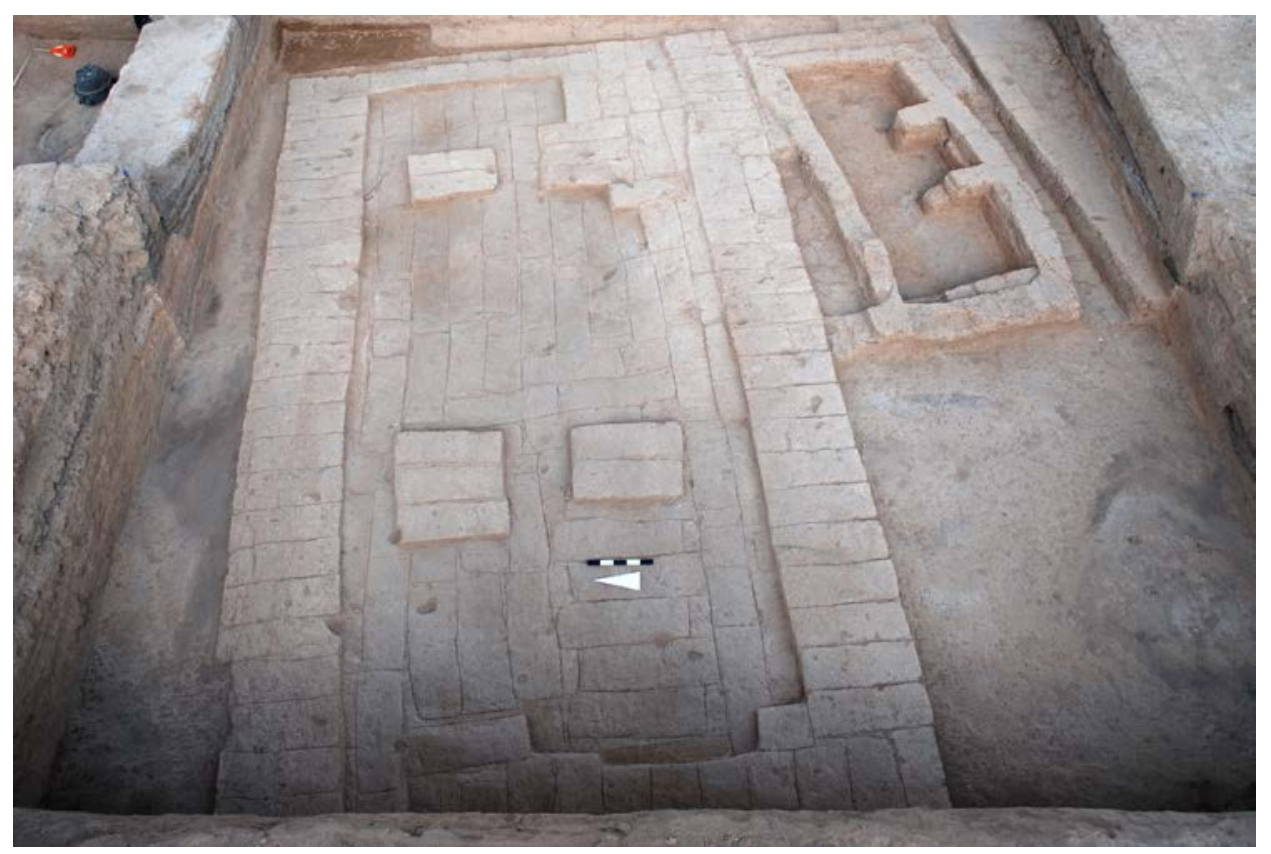

Figure 5. The platform underneath the tripartite building in square $\mathrm{H} 8$ at Tell Sabi Abyad III, ca. 6900 BC. The platform is entirely made of large clay slabs or bricks (photo Peter Akkermans - Tell Sabi Abyad Archive).

The platforms at Tell Sabi Abyad III were constructed in three different ways. The most common were platforms in the form of distinct, elevated rectangles entirely made of large clay slabs (similar to the ones used for house construction), sometimes reinforced by large and roughly hewn gypsum boulders at their edges. A second type of platform consisted of 'boxes' bounded by substantial walls of piled slabs and filled in by masses of soil and other waste

The third way of platform construction was the most opportunistic, as its foundation consisted of the ruins of a previously destroyed building that had been filled in with slabs (ibidem).

All of the platforms were thickly mud-plastered (5 to $15 \mathrm{~cm}$ ), in order to protect them from the elements and to create an even surface for the construction of subsequent architectural features. Most platforms had an irregular height, simply due to the unevenness of the tell surface upon which they were built.

Remarkably enough, no hearths or other installations were found inside the buildings, but such features did occur in small rectangular auxiliary features and in the yards around the tripartite structures.

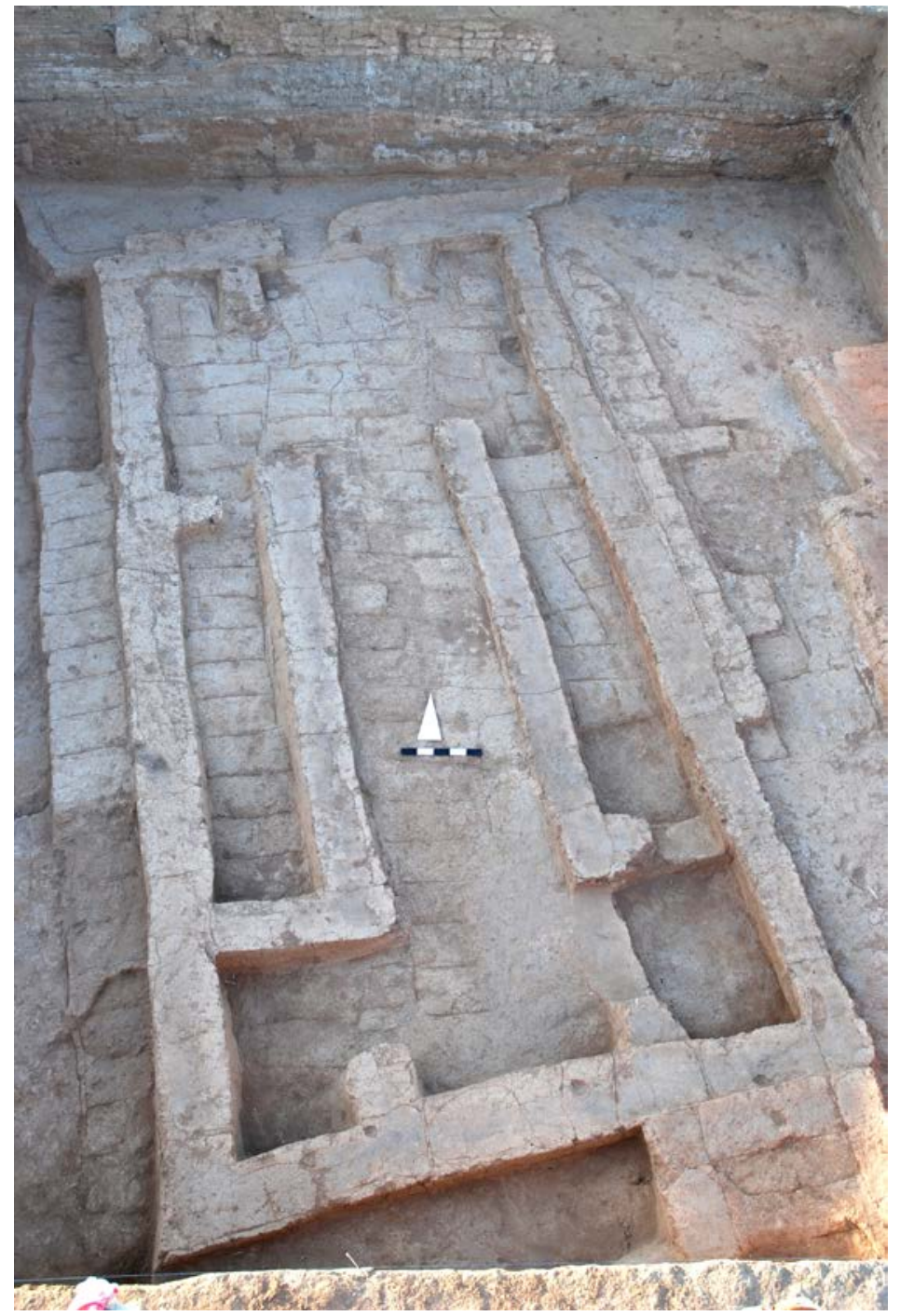

Figure 6. Another tripartite building with long-drawn but narrow rooms, set on a platform. In square J9 at Tell Sabi Abyad III, ca. 7000 $\mathrm{BC}$. Entrance to the building is on the short side from the north (photo $\subset$ Peter Akkermans - Tell Sabi Abyad Archive). 


\section{Auxiliary Architecture and Additional Features}

In addition to the typical tripartite architecture, there were also other forms of rectangular buildings uncovered at Tell Sabi Abyad III, consisting of several small rooms and often provided with a fireplace. On the southern slope of the mound there was a small two-roomed structure oriented northeastsouthwest (Figure 7), which had been rebuilt at least eleven times in roughly the same spot, resulting in a sequence altogether $1.7 \mathrm{~m}$ thick. The architectural uniformity throughout the sequence of reconstruction is remarkable and not unlike that of the tripartite features. Although there were differences in size, the successive buildings retained their overall layout, and doorways and fireplaces (as far as they could be detected in the often dramatically levelled structures) were always on the same sides of the rooms and often rebuilt on exactly the same spot.

The various structures ranged in size from 4.6 by $2.7 \mathrm{~m}$ in the lower layers up to 6.2 by $3.7 \mathrm{~m}$ in the upper layers. Each building appears to have been levelled to its very foundation, with the walls preserved to a height of 10 to, at the most, $45 \mathrm{~cm}$. They were subsequently filled in with mud slabs, bricks and debris thereof, to serve as a solid platform for the next building on top. Usually the newly built structure was not in exact alignment with the previous one but had shifted slightly in size or orientation.

Each of the buildings had two rooms, roughly identical in size, with two short buttresses in the middle dividing the rooms from each other. Occasionally another small space (approximately 1.8 by $1.2 \mathrm{~m}$ ) was added to the main structure, which gave the building an L-shape. The main entrance to the building seems to have been on the south side, usually in the eastern half. The floors and walls had multiple thin layers of mud for plastering. Preserved phytoliths on one of the floors seem to have been bundles of reeds, possibly the remains of matting.
While there were no hearths or the like in the tripartite buildings, such features did occur in the auxiliary structures. A fireplace was nestled in either the northwest or south-west corner of each building and was partly cut into the wall. The hearths, sunk to a depth of $6-11 \mathrm{~cm}$ into the floor, were lined with a low wall of plastered red-burnt clay. The smallest were roughly circular and about $45-50 \mathrm{~cm}$ across, whereas the largest ones were oval and measured about 80 by $125 \mathrm{~cm}$. Their interiors were filled in with ashes as well as (in one case) with small, fire-cracked stones.

Another two-roomed building occurred to the north of the sequence of structures just described, although it differed in two major aspects: first, it was considerably smaller, measuring about 3.25 by 1.75 metres, and, second, it seems to have had only a single use phase. This building, oriented north-south, was divided by a wall with a doorway in the middle into two rooms, each covering approximately 1.2 square metres. The outside entry to the building was present in the northern room, about $60 \mathrm{~cm}$ wide and facing to the west. The southern room had a fireplace in one of its corners, about $60 \mathrm{~cm}$ in diameter and with a low clay wall about $23 \mathrm{~cm}$ in height. In its ashy fill a hammer stone was found. In the southwest corner of the room, there was a concentration of basalt grinders and hammer stones

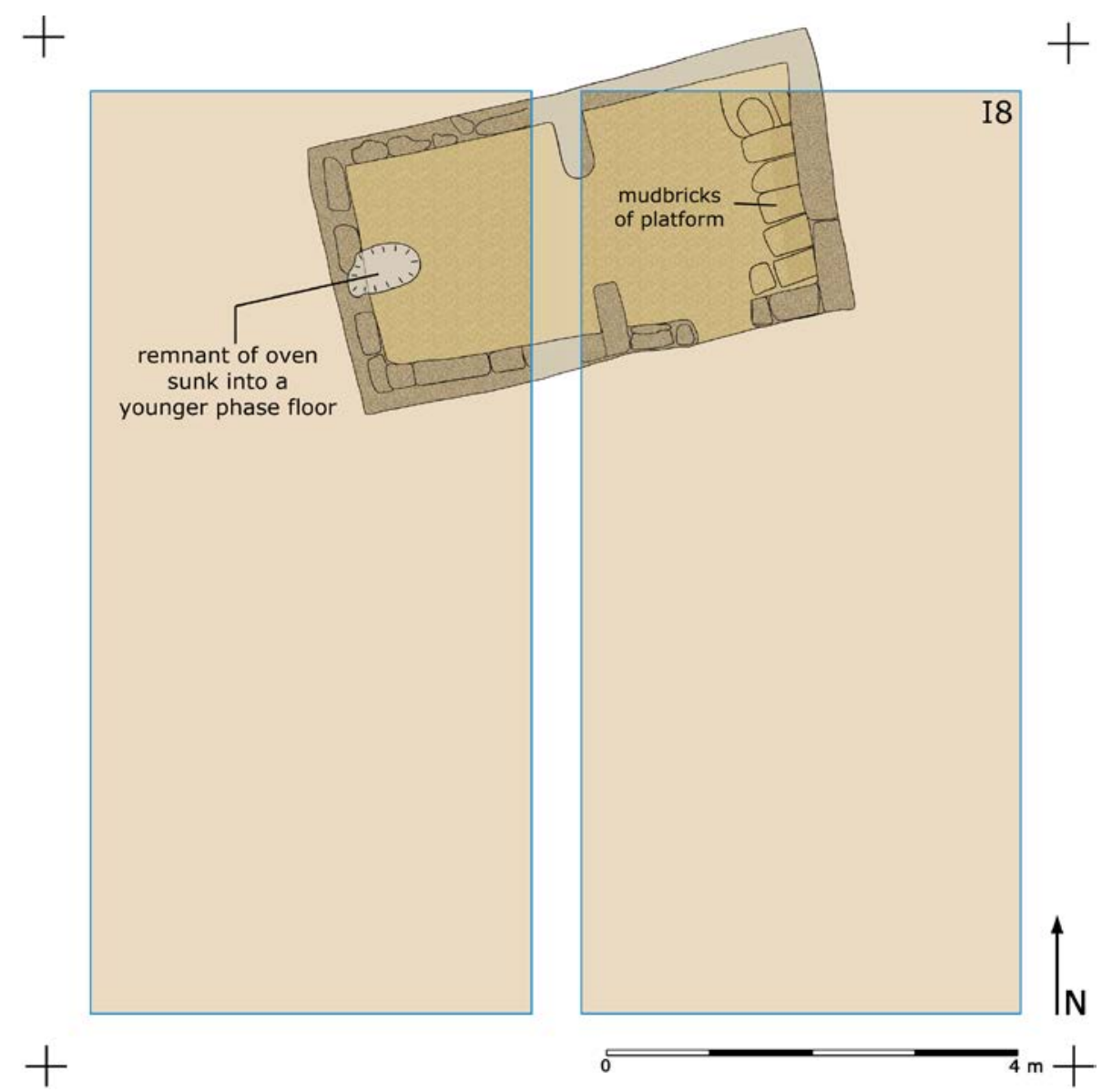

Figure 7. The small two-roomed building in square I8 at Tell Sabi Abyad III, ca, 6800 BC (drawing by Martin Hense - Tell Sabi Abyad Archive). 
on the floor, together with bitumen fragments carrying basketry impressions.

Most likely the tools were once gathered in the bitumen-covered basket (interestingly a similar find was made earlier in a roughly contemporary layer at the nearby mound of Tell Sabi Abyad II; see Verhoeven and Akkermans 2000: 103).

In the large open yards outside the structures there were large pits, up to 5 by $3 \mathrm{~m}$ in extent, $1 \mathrm{~m}$ deep, and entirely filled in with ashes and burnt pieces of clay. Often smaller pits were subsequently sunk into the large ones, likewise filled with ashes. Clay figurine fragments were commonly uncovered in them. Hearths also regularly stood inside the large ash pits. Most likely the large pits represented the main areas for cooking as well as for other activities that involved fire.

\section{Material Culture}

In general the architecture at Tell Sabi Abyad III was virtually devoid of tools or artefactual finds, suggesting that most buildings were entirely emptied of their contents at the time of abandonment. Objects were recovered mainly from the debris layers in the open areas, although both the number and diversity of artefacts at the site was relatively limited. The most common finds were (very) small stone bowls, pieces of bitumen with basketry impressions, bone awls, basalt grinders, hammer stones (Figure 8), stone axes, clay figurines, and beads of stone, bone or clay. Many objects were in a highly fragmentary state, perhaps due to continuous curation. Noteworthy exceptions were the miniature stone bowls $3-4 \mathrm{~cm}$ in diameter, many of which remained intact.

Fragments of small clay human and animal figurines that had traces of (secondary) firing deserve special mention. They were usually found together in substantial quantities, rarely as single pieces, and occurred almost exclusively in the large pits that were filled with ashes and the remnants of fireplaces. It seems that they were thrown into the fire, either complete or broken, and that they subsequently remained in the ashes (as part of a ritual). The practice of throwing and breaking figurines in the fires was repeated over and over again.

The local occupational sequence has yielded small quantities of very early ceramics in layers immediately above deposits with no pottery all. The typical pottery, which had yet to develop into the mass-produced ware so characteristic of the later seventh millennium BC, has been treated in detail elsewhere (Nieuwenhuyse et al. 2010); here we may briefly recall its characteristics. The handmade ceramics were mainly mineral-tempered, smoothed or burnished, with regular wall profiles and rims, and an even wall thickness. Surface colors ranged from dark-grey to pale brown. Occasionally, darker colors appear to have been caused by the use of the vessel over a fire, and traces of black soot are not uncommon. Remarkably enough, this early pottery was occasionally decorated by slipping and painting. The designs were simple and included parallel diagonal lines, diagonal lines in alternating directions, cross-hatching and diagonal waves. Similarly decorated ceramics have been retrieved at Seker al-Aheimar on the Khabur and at Akarçay on the Turkish Euphrates (Nishiaki and Le Mière 2005; Arimura et al. 2000). Considering that pottery occurred at Tell Sabi Abyad III in what seems to have been a fully-fledged form, it is not excluded that the ceramics arrived at the site through exchange networks, perhaps from north-eastern Syria or Anatolia

(Nieuwenhuyse et al. 2010).

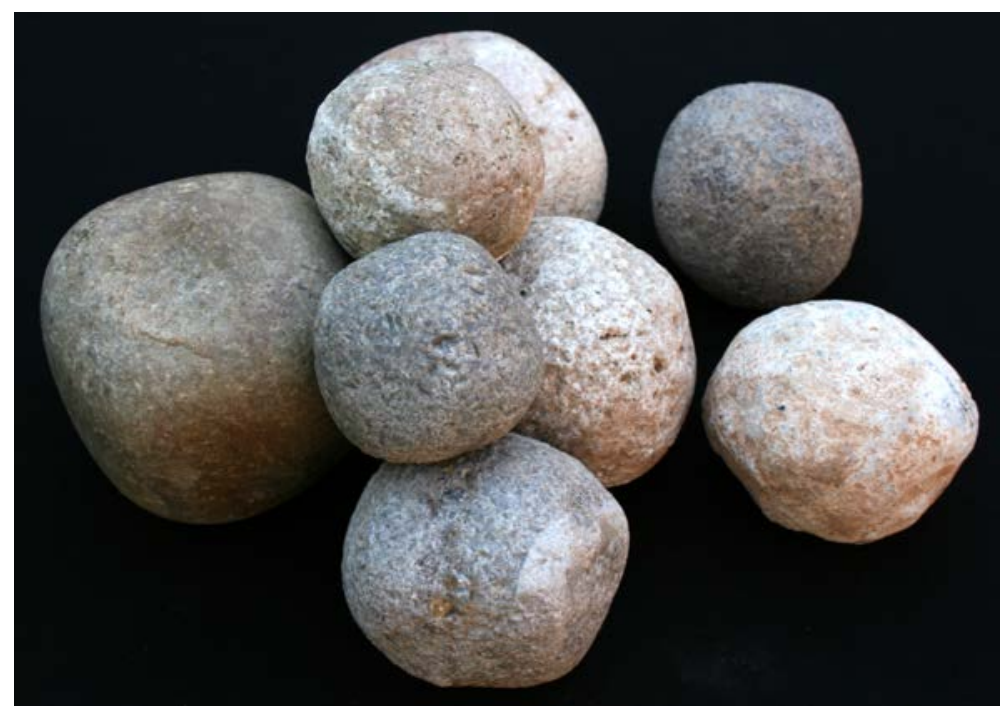

Figure 8. A selection of hammer stones from Tell Sabi Abyad III, ca. $6900 \mathrm{BC}$. The stones vary in diameter from 3.4 to $6.6 \mathrm{~cm}$ (photo $\subset$ Peter Akkermans - Tell Sabi Abyad Archive).
There were other products that came to Tell Sabi Abyad III through trade, such as basalt for the production of ground tools, which may have been obtained in the Turkish piedmont, some $100 \mathrm{~km}$ to the north of the site. One complete basalt grinder was in the form of a boot (Figure 9) and was found in the room fill of a small auxiliary building, next to a tripartite structure.

It resembles finds at Pre-Pottery Neolithic Halula on the Euphrates (see Molist 1996: $125 \mathrm{ff}$ and fig. 1, no. 5). Another product that was definitely not local was bitumen, used for making plaited basketry waterproof and hence suitable for 


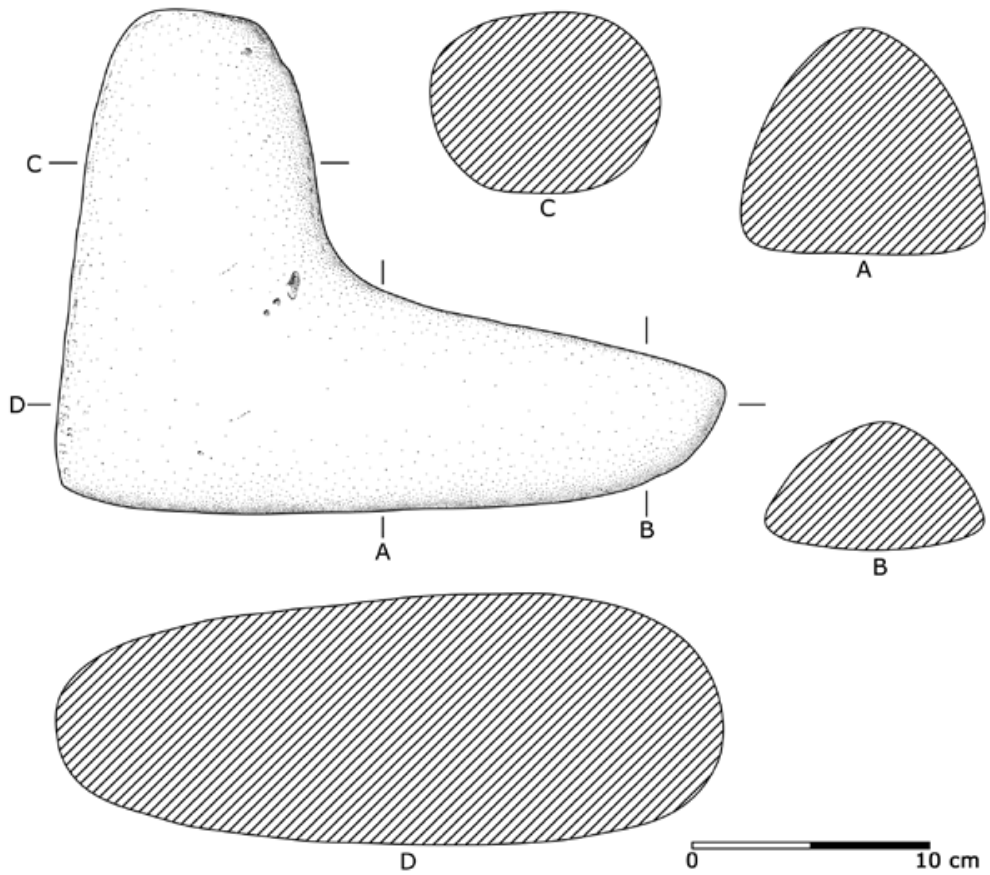

Figure 9. A basalt grinding stone in the shape of a boot. Tell Sabi Abyad III, ca. 6800 BC (drawing by Martin Hense - Tell Sabi Abyad Archive).

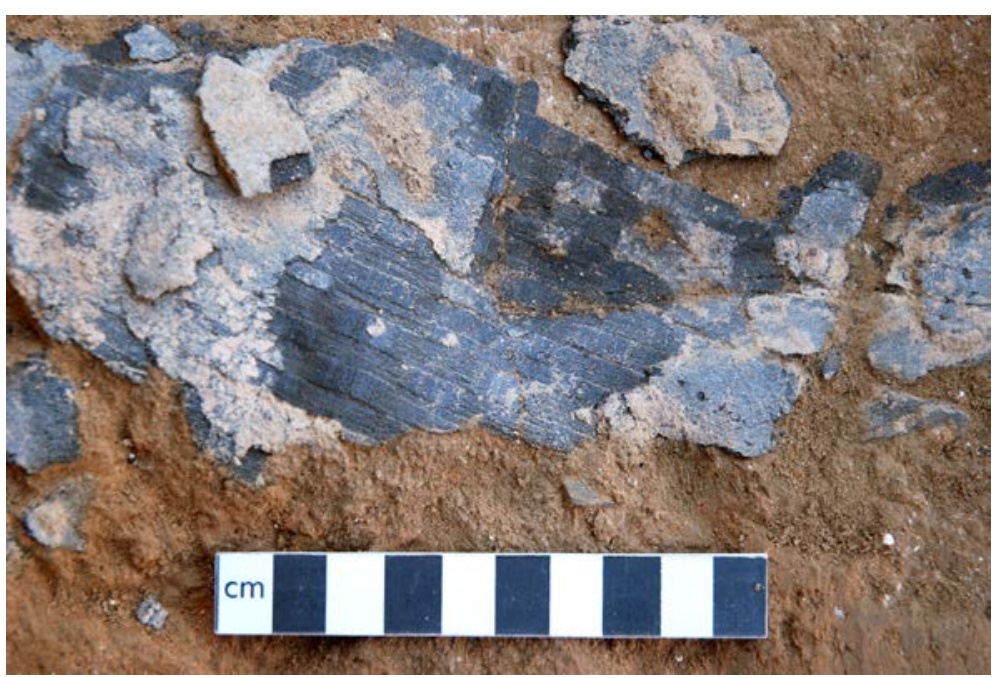

Figure 10. Fragment of bitumen with basket imprints. Tell Sabi Abyad III, ca. 6900 BC (photo @ Peter Akkermans - Tell Sabi Abyad Archive). if not hundreds of baskets in the local Neolithic communities (cf. Akkermans and Verhoeven 1995; Duistermaat 1996).

\section{Life Histories and Architectural Meanings}

The architecture at Tell Sabi Abyad III, with its remarkable uniformity, both in the tripartite houses and the other, auxiliary structures, must have required not only careful planning but also clear and enduring perspectives on the definition of place and dwelling. These were likely supported by the community at large for centuries, with little or no room for individual preferences. There must have been strong social conventions and fundamental choices that expressed common identities and experiences (and the reflection thereof in architecture), which may have helped to organise and bind together the local community.

It is not easy to explain the apparent need or wish for such strictly tripartite architecture and any meanings attached to it. The buildings, it seems, were intended not only for domestic purposes such as living and sheltering but also carried social connotations, as products of social values, ideals, and relations. They may have actively contributed to the local social fabrics, with their shape, size, and construction being the result of a series of deliberate choices within a range of equally viable options, on the basis of past experiences and perceived opportunities and constraints. Once these decisions were made, they implied an attachment to prevailing values, with their consistency perhaps understood as 'the way things are always done' (see the contributions in Stark 1998). The local community at Tell Sabi Abyad III was undoubtedly aware of different ways of constructing buildings but adopted them only selectively for its purposes. In this respect it is important to realize that the tripartite layout became evident only in the initial planning and conceiving of the houses; once they were fully raised, they obscured their complex internal layout from external evaluation and were, at least in their exterior appearance, simple rectangular buildings (Figure 11). Hence it is, we believe, reasonable to conclude that, from its very inception, 

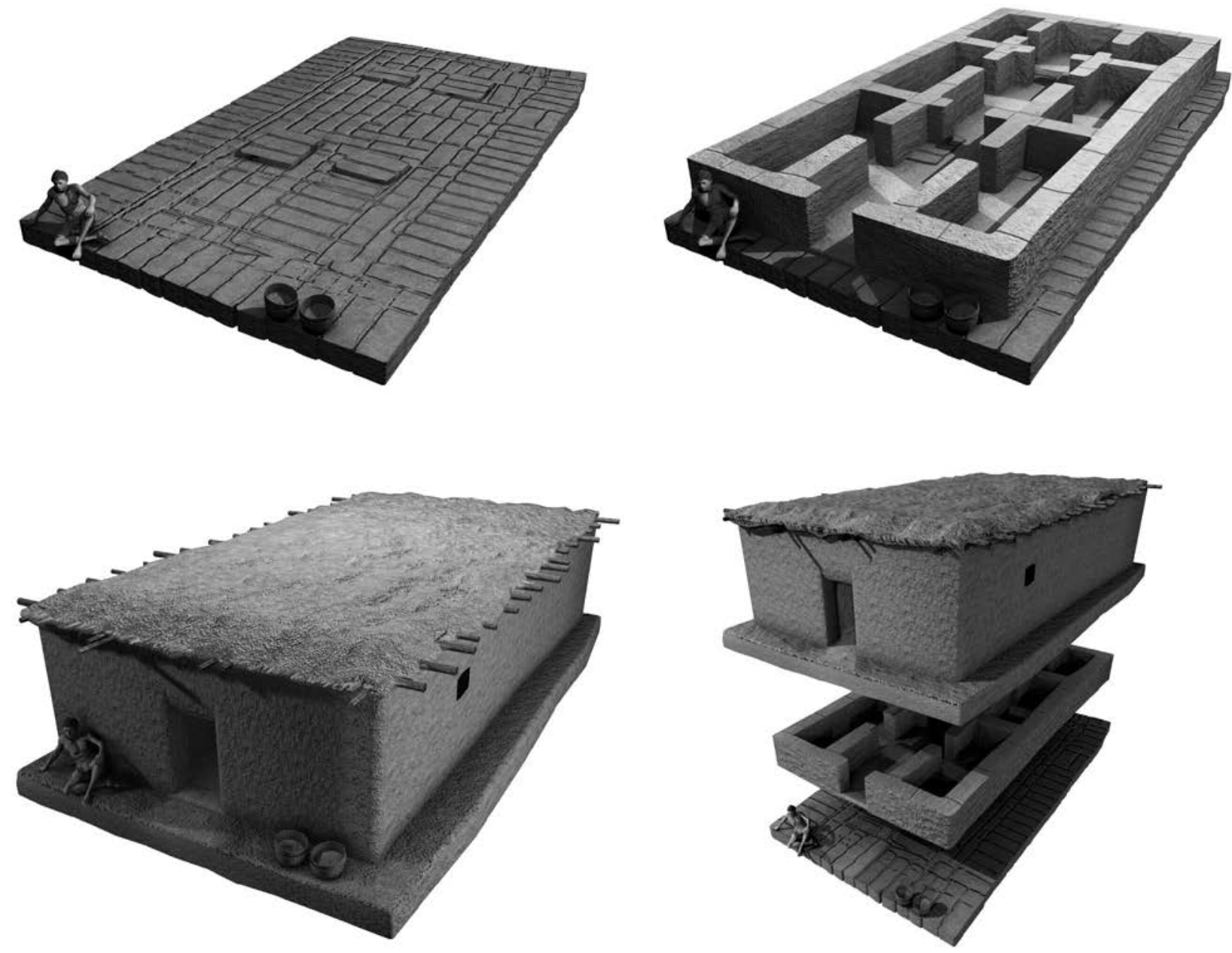

Figure 11. Reconstruction of the platform and the tripartite building atop in square H8. Tell Sabi Abyad III, ca. 6900 BC BC (drawing by Mikko Kriek - Tell Sabi Abyad Archive).

the tripartite architecture blended ordinary domestic use with considerable non-utilitarian, symbolic content and spirituality (see for example Bailey 1990; Barrie 2010; Banning 2011; Moore 2012 on the multiple dimensions of houses: material, functional, social, economic, ritual, etc.).

Significantly, once the tripartite buildings were completed and in daily use, they were minimally modified, expanded or renovated. They remained remarkably intact and unaltered, with no features added or erased, in stark contrast to the architecture from the later seventh millennium $\mathrm{BC}$ at the various mounds of Tell Sabi Abyad, which was in a continuous process of change (see e.g. Akkermans 2013; Akkermans et al. 2014).

We are still in the dark about the precise longevity of the various buildings at Tell Sabi Abyad III, but it may have been for only a few decades within the span of a single generation. Useful insight in this respect comes from the hundreds of radiocarbon dates collected from the occupational sequence of nearby Tell Sabi Abyad I, which suggested that buildings in the seventh millennium BC typically lasted between 15 and 40 years, and that most features were occupied for periods on the order of 20-30 years (see Van der Plicht et al. 2011; Akkermans 2013). It is tempting to conclude that the tripartite houses at Tell Sabi Abyad III were inhabited for no more than one generation, and that the buildings were left to their fate at the time of the occupants' death or another event which ended the household life cycle (cf. Akkermans 2013: 70). When the houses came to an end, they were left to fall into ruins and in the majority of cases were gradually filled in with collapsed wall remnants and domestic waste. Occasionally one or more infant burials were dug into them (in the corners of former rooms), suggesting that the local abandonments were considered to be more or less permanent (Figure 12).

In this respect it is relevant to note that, with very few exceptions, the tripartite dwellings were never rebuilt in exactly the same location or on the same alignment. Likewise it appears that the massive platforms were rarely or not at all re-used for later building purposes. In other words: earlier but still extant building remains were hardly or not used for foundation purposes. 


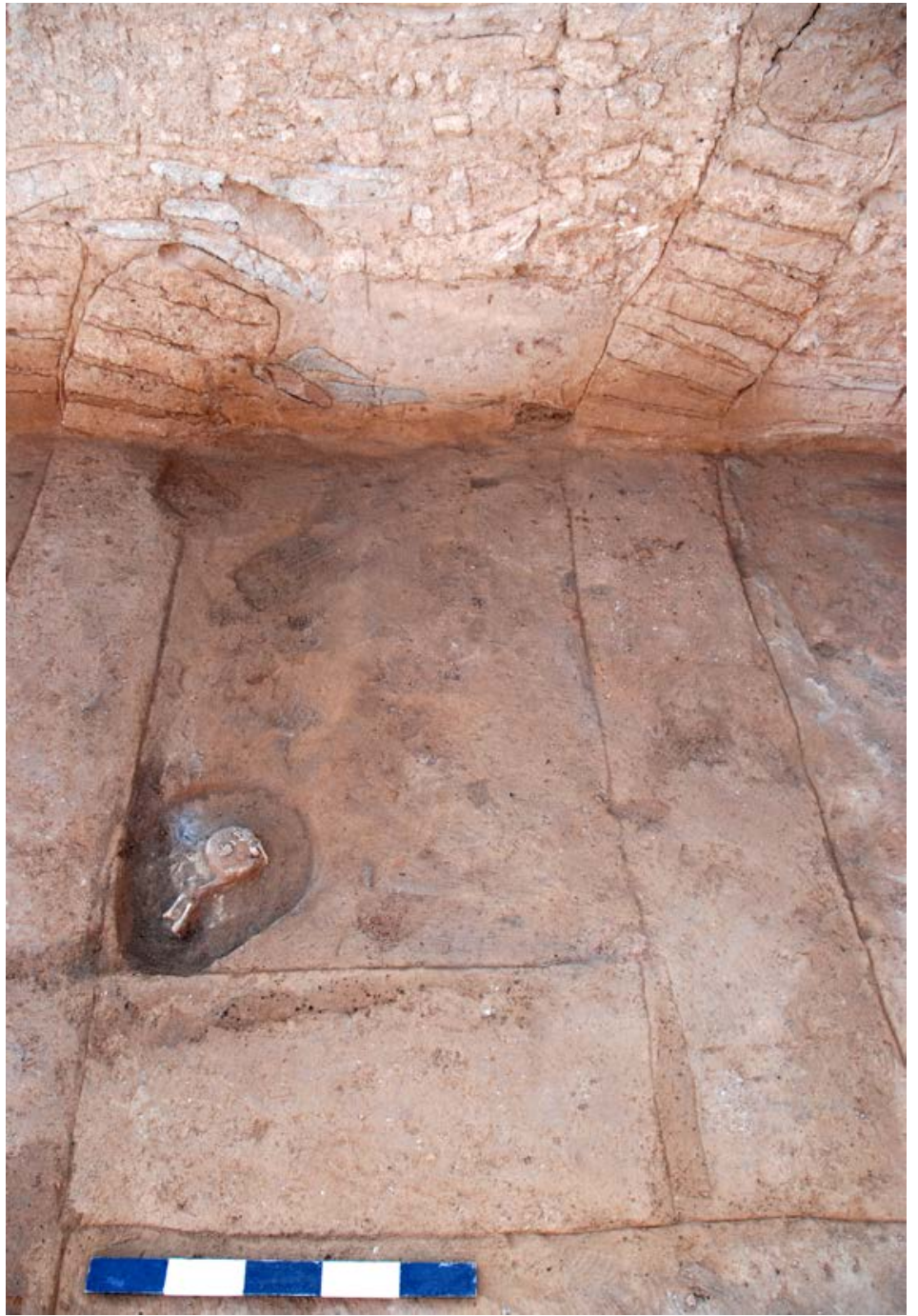

Figure 12. An infant burial dug into the corner of room of an abandoned tripartite building. Tell Sabi Abyad III, ca. 6700 BC (photo (c) Peter Akkermans - Tell Sabi Abyad Archive).
Whenever rebuilding was anticipated, the previous, ruined structures were razed until their walls remained to a height of only $10-20 \mathrm{~cm}$, and until their rooms were entirely filled in with wall fragments, etc.

Subsequently the new architecture was erected in roughly the same area but with a very different orientation (obliquely or perpendicular to the earlier features), and often partly cut into the underlying house remnants (cf. Figure 13).

The continual and wholesale replacement of the tripartite architecture (from the platform to the subsequent house), with little or no re-use of earlier features, emphasizes the uniqueness of each building and the constantly repeated and very considerable labour efforts that were invested in each and every structure. It also accentuates the apparent attempt at uniformity in size and layout, which is re-created again and again from one building to another throughout the sequence of settlement. This observation supports our earlier conclusions, namely that the tripartite features at Tell Sabi Abyad III were more than merely utilitarian vehicles for the daily routines of living and working. Rather, they must have also held a substantial social and symbolic prominence,

Figure 13. A sequence of tripartite architecture in square $\mathrm{H} 8$ at Tell Sabi Abyad III, ca. 69006800 BC. The earliest structure, oriented roughly north-south, is partly shown on the right below. The next building, atop of the previous one and oriented east-west, is depicted on the right above. The third, and youngest, building oriented northeastsouthwest is shown on the left (photo $\odot$ Peter Akkermans - Tell Sabi Abyad Archive).

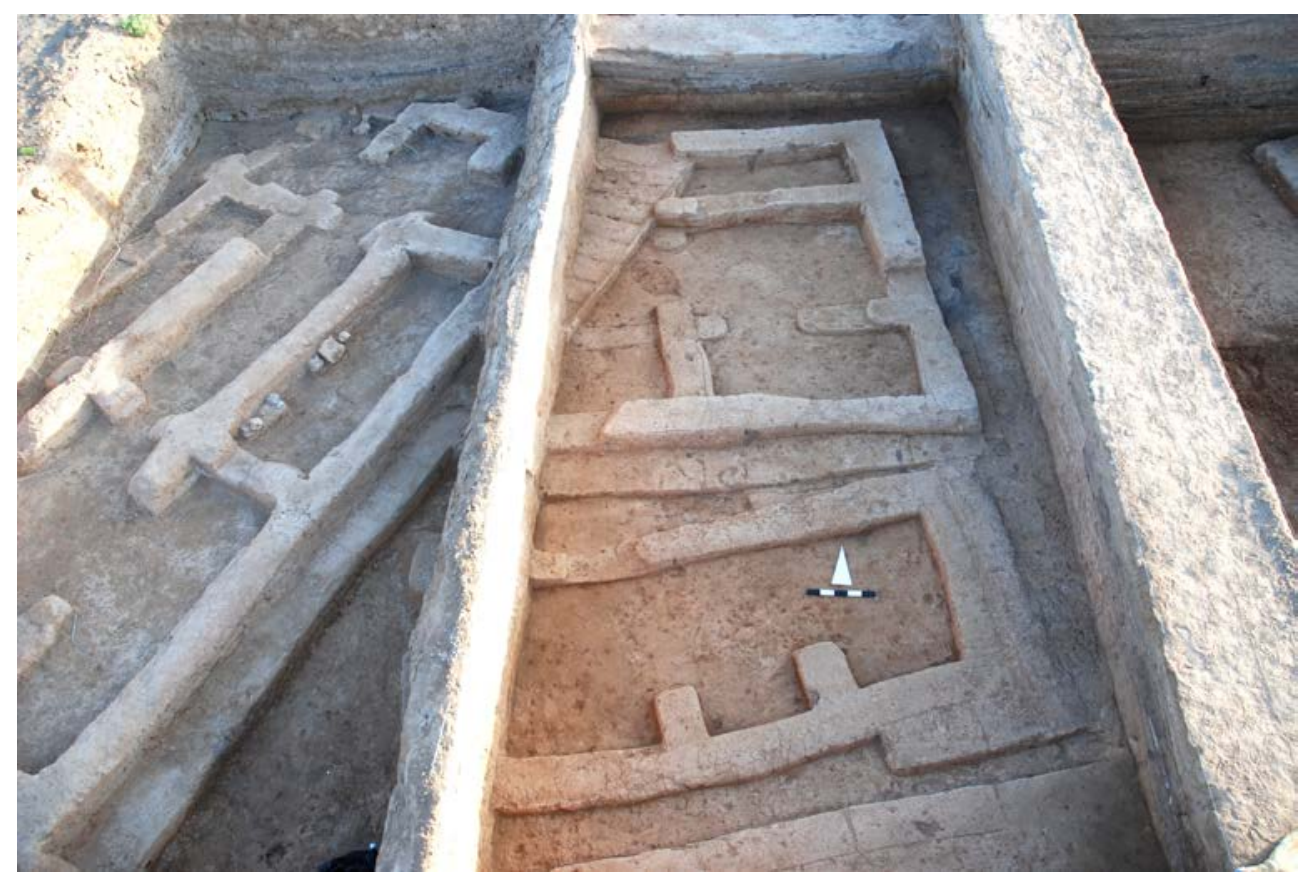


which, on the one hand, made clear reference to the past through their architectural consistency in layout and, on the other hand, required constant renewal through generational reconstruction and relocation of the dwellings. Architecture and material culture in general actively mimic social realities, as they both create, and are created by, the structure of local social consciousness (see, for example, Hodder 1982; Bailey 1990). Although each of the tripartite buildings were rather short-lived, their multitude and uniform repetition over the generations helped to ensure both social continuity and community cohesion. These social relationships may have become part of the "natural order' and as such, may have received the status of ever-existing and non-discussible. In this respect the focus on repetition and continuity with the past also may have had political or ideological motivations, as it legitimises and naturalises the status quo, including any relations of dominance (see the various contributions in Miller and Tilley 1984).

\section{Bibliography}

Akkermans, Peter M. M. G. 2013. Living Space, Temporality and Community Segmentation Interpreting Late Neolithic Settlement in Northern Syria. In O. P. Nieuwenhuyse, R. Bernbeck, P. M. M. $\mathrm{G}$. Akkermans and J. Rogash (eds), Interpreting the Late Neolithic of Upper Mesopotamia: 63-75. Turnhout, Brepols.

Akkermans, Peter M. M. G., Brüning, M. L., Huigens, H. O. and Nieuwenhuyse, O. P. (eds) 2014. Excavations at Late Neolithic Tell Sabi Abyad, Syria - The 1994-1999 Field Seasons. Turnhout, Brepols Publishers.

Akkermans, Peter M. M. G., Brüning, M. and Kaneda, A. 2011. Foundation or Rendez-vous? Constructing Platforms in Late Neolithic Syria. In B. S. Düring, A. Wossink and P. M. M. G. Akkermans (eds), Correlates of Complexity: 1-13. Leiden, Nederlands Instituut voor het Nabije Oosten.

Akkermans, Peter M. M. G., Cappers, R., Cavallo, C., Nieuwenhuyse, O., Nilhamn, B., and Otte, I. 2006. Investigating the Early Pottery Neolithic of Northern Syria: New Evidence from Tell Sabi Abyad. American Journal of Archaeology 110: 123-156.

Akkermans, P. M. M. G. and Verhoeven, M. 1995. An Image of Complexity: The Burnt Village at Late Neolithic Tell Sabi Abyad, Syria. American Journal of Archaeology 99/1: 5-32.
Arimura, M., Balkan-Atli, M., Borell, F., Cruells, W., Duru, G. Erim-Özdogan, A., Ibanez, J. Maede, O., Miyake, Y., Molist, M. and Özbasaran, M. 2000. A New Neolithic Settlement in the Urfa region: Akarçay Tepe, 1999. Anatolia Antiqua 8/1:227-255.

Bailey, D. W. 1990. The Living House: Signifying Continuity. In R. Samson (ed.), The Social Archaeology of Houses: 19-48. Edinburgh, Edinburgh University Press.

Banning, E. B. 2011. So Fair a House: Göbekli Tepe and the Identification of Temples in the Pre-Pottery Neolithic of the Near East. Current Anthropology 52/5: 619-660.

Barrie, T. 2010. The Sacred In-Between: The Mediating Roles of Architecture. Oxford, Routledge.

Connan, J., Nieuwenhuyse, O. P., Van As, A. and Jacobs, L. 2004. Bitumen in Early Ceramic Art: BitumenPainted Ceramics from Late Neolithic Tell Sabi Abyad (Syria). Archaeometry 46/1: 115-124.

Duistermaat, K. 1996. The Seals and Sealings. In P. M. M. G. Akkermans (ed.), Tell Sabi Abyad: The Late Neolithic Settlement: 339-401. Leiden and Istanbul, Nederlands Historisch-Archaeologisch Instituut.

Hodder, I. 1982. Symbols in Action. Cambridge, Cambridge University Press.

Miller, D. and Tilley, Ch. (eds) 1984. Ideology, Power and Prehistory. Cambridge, Cambridge University Press.

Molist, M. (ed.) 1996. Tell Halula (Siria)-Un yacimiento Neolítico del valle medio del Éufrates. Campañas de 1991 y 1992. Barcelona, Ministerio de Education y Cultura. Moore, J. D. 2012. The Prehistory of Home. Berkeley, Los Angeles and London, University of California Press.

Nieuwenhuyse O. P., Akkermans, P. M. M. G. and Van der Plicht, J. 2010. Not So Coarse, Nor Always Plain - The Earliest Ceramics of Syria. Antiquity 84/323: 71-85.

Nishiaki, Y. and Le Mière, M. 2005. The oldest pottery Neolithic of Upper Mesopotamia: New evidence from Tell Seker al-Aheimar, The Khabur, northeast Syria. Paléorient 31/2: 55-68.

Stark, M T. (ed.) 1998. The Archaeology of Social Boundaries. Washington and London, Smithsonian Institution Press.

Van der Plicht, J., Akkermans, P. M. M. G., Nieuwenhuyse, O P., Kaneda, A. and Russell, A. 2011. Tell Sabi Abyad: Radiocarbon Chronology, Cultural Change and the 8.2 ka Event. Radiocarbon 53/2: 229-243.

Verhoeven, M. and Akkermans, P. M. M. G. (eds) 2000. Tell Sabi Abyad II - The Pre-Pottery Neolithic B Settlement. Leiden and Istanbul, Nederlands HistorischArchaeologisch Instituut. 